DOI 10.37882/2223-2982.2021.01-2.19

\title{
ИНОЯЗЫЧНЫЕ ВКРАПЛЕНИЯ В ИСПАНСКИХ РЕКЛАМНЫХ ТЕКСТАХ
}

\section{FOREIGN-LANGUAGE ELEMENTS IN SPANISH ADVERTISING TEXTS}

Yu. Toporkova

Summary: The article focuses on the problem of translation of foreignlanguage elements in Spanish advertising texts. The peculiarities of functioning of foreign inclusions in the advertisements of Spanish fashion goods are investigated. The foreign-language elements in Spanish advertising texts are singled out: English and French inclusions, barbarisms, intertextual units, allusions. The Spanish advertisements and their translations are analyzed. It's found out that the main translation techniques used to translate foreign-language elements are direct translation, approximate translation, pragmatic adaptation, loose translation.

Keywords: foreign-language elements; barbarism; allusion; direct translation; approximate translation; loose translation; pragmatic adaptation.

\author{
Топоркова Юлия Александровна \\ К.п.н., дочент, ФГАОУВО «Севастопольский \\ государственный университет» \\ yulia.toporkova2014@yandex.ru
}

Аннотация: В статье рассматривается проблема перевода иноязычных вкраплений в испанских рекламных текстах. Исследованы особенности функционирования иноязычных вкраплений в рекламе товаров испанской модной индустрии. Выяснено, что иноязычная лексика в испанских рекламных объявлениях представлена английскими и французскими вкраплениями, варваризмами, интертекстуальными отсылками, аллюзиями. Проанализированы тексты испанских рекламных сообщений и их переводы. Установлено, что основными приемами перевода иноязычных вкраплений являются: прямой перевод, приближенный перевод, прагматическая адаптация, объяснительный перевод.

Ключевые слова: иноязычное вкрапление; варваризм; аллюзия; прямой перевод; приближенный перевод; объяснительный перевод; прагматическая адаптация.
Л юбой рекламный текст обладает прагматической направленностью: его главная коммуникативная цель заключается в побуждении реципиента к приобретению продукции [5].

Поэтому в процессе перевода рекламы для реализации данной коммуникативно-прагматической задачи, прежде всего, необходимо обращать внимание на сохранение апеллятивной функции текста в целевой культуре [1, с. 2].

При этом заложенная в рекламе скрытая идеология и социокультурный подтекст значительно затрудняют работу переводчика. Прежде чем воспроизвести рекламное сообщение на другом языке необходимо обнаружить это идеологическое содержание и решить, каким образом передать его в переводе, если это сохранение обоснованно. Таким образом, текст перевода может способствовать искоренению или, напротив, укреплению социально-культурных стереотипов [11, с. 62].

В этом аспекте перевод рекламных объявлений неразрывно связан с проблемой передачи иноязычных вкраплений. По словам С.В. Коломиец, иноязычные вкрапления - это языковые единицы, не ассимилированные или частично ассимилированные к системе заимствующего языка, представляющие код гостевого языка. Появление иноязычных вкраплений в тексте рекламных объявлений продиктовано как экстралингвистическими факторами (политические, экономические, культурные связи между народами-носителями языков), так и лингвистическими, которые связаны с реализацией их номинативной, прагматической, компрессирующей, аттрактивной функций [2, с. 270].

И.Ю. Мигдаль подчеркивает, что такие слова имеют эквиваленты в составе лексики переводящего языка, но стилистически от них отличаются: они закреплены в той или иной сфере общения как специальные наименования или используются как выразительное средство, придающее речи особую экспрессию [3, с. 32].

Цель данной работы - рассмотреть иноязычные вкрапления в текстах испанской рекламы и их воспроизведение в переводе. Исследуем особенности функционирования данной лексики в рекламе товаров модной индустрии. Ведь мода - это именно та сфера, где важно учитывать эстетические предпочтения, а также психологические и социально-культурные характеристики целевой аудитории. Поэтому при выходе рекламы на новый рынок важно тщательно изучить традиции, взгляды и вкусы местного населения; а переводчику, в свою очередь, приходится решать как языковые, стилистические, так и социолингвистические проблемы перевода, адаптируя рекламное сообщение к реалиям другой страны. 
Анализ рекламных объявлений официальных сайтов испанских брендов, прежде всего, позволил выявить наличие большого количества английских и французских вкраплений, а также варваризмов. Приведем примеры перевода англоязычных элементов в текстах испанской рекламы:

Think pink. Las posibilidades a la hora de combinar esta gargantilla son infinitas. Imaginación al poder y looks nuevos en un instante [10]. - Фантазируй. Перед тобой открыты безграничные возможности комбинирования колье-чокера. Дай волю фантазии, и новые образы будут готовы в одно мгновение [13]. В данной рекламе розового колье из серебра фигурирует слоган «Think pink» - «Думай noрозовому!», содержащий рифму и отсылку к цвету самого изделия. Было бы нецелесообразным оставить данное словосочетание в переводе, так как русскоговорящим потребителям, не владеющим английским языком, оно было бы непонятно. Фраза было переведена нейтрально как «Фантазируй», причем переводчик не стал прибегать к стилистической компенсации для передачи стилистического потенциала иноязычного вкрапления. Кроме того, такой вариант перевода привел к возникновению в рекламном сообщении корневого повтора, поскольку в последнем предложении присутствует слово «фантазия»: «Дай волю фантазии, и новые образы будут готовы в одно мгновение». Тем не менее, такое совпадение, на наш взгляд, нельзя назвать неудачным.

В ходе изучения испанских рекламных текстов выяснено, что иноязычные вкрапления могут сопровождаться графическими стилистическими средствами, напримep: Incorpora una joya *minimal ${ }^{*}$ para subrayar tu *outfit* [10]. - Добавьте *минималистский* аксессуар, чтобы подчеркнуть свой * наряд* [13]. Déjate llevar por la *fashion shopping* y regálate este reloj en código *black* [10]. - Пoзвольте себе модный шопинг и подарите себе эти часы с кодом *черный* [13].

В приведенных выше примерах для реализации аттрактивной функции, исследуемые лексические единицы выделяются астерисками. В русскоязычной версии рекламных сообщений данные знаки также сохранены переводчиком для привлечения внимания целевой аудитории.

Таким образом, сопоставительный анализ текстов оригинала и перевода рассматриваемых рекламных сообщений показал, что в русских вариантах англоязычные вкрапления встречаются гораздо реже. Более того, переводчики избегают больших скоплений данных лексем в пределах одного русскоязычного текста: это затрудняет восприятие информации рецептором рекламного сообщения и может произвести обратный эффект - оттолкнуть потенциального потребителя.

Однако иногда переводчики сами вводят в текст перевода широко известные варваризмы, которых не было в оригинале, как, например, это было сделано при переводе рекламы футболок и топов от Mango:

Las camisetas y tops son ideales para cualquier ocasión. Tenemos camisetas de manga corta y manga larga, camisetas de tirantes y tops, camisetas básicas y estampadas en todos los estilos. Un básico en tu armario fácil de combinar para conseguir el look más acertado [12]. - Футболка или mon - идеальный вариант для любого случая. У нас Вы найдете футболки с коротким и с длинным рукавом, топы на бретелях, базовые модели, различные принты и расиветки. Must-have в Вашем гардеробе, который легко сочетать для создания любого образа [4]. В рассматриваемом переводе нейтральное испанское слово «básico» («базовый») заменяется англицизмом «must-have». Эта лексическая единица значительно распространена в сфере моды в разных языках, и постоянно встречается на страницах женских журналов. Вероятность того, что она будет непонятна русскоговорящим покупательницам, очень мала. К тому же, за счет данной замены высказывание стало более экспрессивным.

Проанализируем переводы французских вкраплений. Cuando un anillo tiene mil caras te permite jugar a combinarlo con diferentes tendencias y estilos. Será como abrir una puerta a un universo de nuevas combinaciones, aportará aire fresco a tu armario añadiéndole el famosísimo «je ne sais quоі» [10]. - Когда у кольча столько обличий, оно отлично вписывается в любые тренды и стили. Этот аксессуар - пропуск в мир стильных комбинаций. Он вдохнет новую жизнь в ваш гардероб - и привнесет в ваш образ нечто неуловимо прекрасное [13]. Французская фраза «је ne sais quoi» буквально переводится как «Я не знаю что». B XVIII веке она была распространена в сфере искусства и обозначала красоту, которую невозможно выразить словами. На русский она обычно переводилась как «неизъяснимый». Сейчас фраза известна, но уже не так, как раньше, и будет понятна ограниченному числу российских потребителей, и потому в переводе стоит от нее отказаться, что и было сделано. В русском рекламном сообщении это иноязычное вкрапление было переведено с французского как «нечто неуловимо прекрасное».

Однако стоит отметить, что случаи сохранения французского вкрапления в переводе на русский все же встречаются. Обратимся к соответствующему примеру: La naturaleza y el romanticismo combinan de manera magistral en esta exquisita pieza de edición limitada, inspirada por la exuberante elegancia del pavo real. Una joya fantástica en la que diseño y calidad se aúnan expresando el «savoir-faire», personalidad y estilo único del que Magerit imbuye a todas sus creaciones [7]. - Природа и романтика мастерски объединены в этом, с ограниченным тиражом изделии, вдохновленном пышной элегантностью павлина. Фантастические жемчужины, дизайн и качество которых воплощают «savoir-faire», личность и уникальный стиль, который наполняет все творения Magerit [6]. Лексическая единица «savoir-faire» - варваризм французского 
происхождения, точнее галлицизм. Ее русскими эквивалентами являются «ноу-хау», «умение», «опыт», однако в данном контексте подобный вариант перевода не соответствовал бы стилистической окрашенности объявления с рекламой изысканного ювелирного украшения. Следовательно, первоначальная форма вкрапления сохранена при переводе, во-первых, потому что данная фраза все же функционирует в современном русском языке и знакома, хотя и не всем, но многим его носителям; во-вторых, с ее помощью переводчику удается передать колорит и образность оригинального текста.

Приведенный выше пример перевода иноязычного вкрапления позволяет также говорить о том, что эффективность воздействия данного рекламного объявления обусловлена приемом «интертекстуальности» - намеренного введения в текст перевода отсылок на другие тексты или жанры, содержащие известные факты, клишированные фразы или цитаты с целью привлечения потенциального потребителя [1, с. 10-11].

В ходе изучения лексики испаноязычных рекламных текстов нами было выявлено значительное количество подобных интертекстуальных, аллюзивных отсылок к неким универсалиям, общеизвестным историческим, литературным фактам, прецедентным текстам. Безусловно, подобные аллюзивные вкрапления делают образ продукта более ярким, выразительным и узнаваемым, что облегчает процесс его передачи при переводе. Так, например, в рекламе коллекции Polynesia oт Giverola coдержится историческая аллюзия: Una de las islas más famosas de la Polinesia Francesa es la isla de Bora Bora. Gracias a su hermosa laguna de perlas, es considerada el lugar más romántico de la Tierra. Incluso James Cook, el primer europeo que visitó esta isla exótica, no pudo resistir su belleza y la llamó «la perla del Océano Pacífico» [8]. - Один из самых известных островов Франиузской Полинезии - остров Бора-Бора. Благодаря своей красивейшей перламутровой лагуне, он по праву считается самым романтическим местом на Земле. Даже Джеймс Кук, первый европееи, который посетил этот экзотический остров, не устоял перед его красотой и прозвал его «жемчужиной Тихого океана» [9]. В данном рекламном сообщении упоминается Джеймс Кук и его экспедиция в Тихий океан. Его личность и его открытия известны во всем мире, так что сохранение аллюзии при переводе полностью оправданно.

Обратимся к переводу рекламы ювелирного украшения, где содержится мифологическая аллюзия на Медузу: Los mitos y leyendas de la Antigua Grecia han servido de inspiración para muchas creaciones. La colección «Mythology» se centra en la poderosa figura de Medusa, quien, entrelazada con uno de los animales de más simbolismo en la mitología, la serpiente, muestra el verdadero significado de «belleza mortal» [7]. - Мифы и легенды Древней Греции служили вдохновением для многих творений. Коллекция «Mythology» сфокусирована на могучей фигуре Медузы, которая переплетается с одним из самых символических животных - змеёй, показывая, что это действительно «смертельная красота» [6]. Как видим, в тексте оригинала данного рекламного объявления присутствует определенная степень метафоричности, которая сохранена переводчиком, в том числе путем прямой передачи данной аллюзии. Таким образом, сохранение аллюзий при переводе стилистически-окрашенных рекламных объявлений является целесообразным: это, с одной стороны, позволяет ярко и точно передать экспрессивность оригинального текста, а с другой, апеллировать к общечеловеческим культурным ценностям и воздействовать на эмоциональное восприятие реципиента, а значит, оказывать должный эффект на потенциального покупателя.

Рассмотрим еще один пример на основе текста рекламы кольца коллекции Manta Ray от Giverola и его перевода: Para la tribu maorí, Manta Ray era un poderoso talismán. Este habitante del océano velaba por los aventureros libres y valientes y su energía sagrada los ayudaba a adaptarse a cualquier situación y los protegía de las emociones negativas de otras personas. El anillo «Manta Ray» le protegerá y le mostrará la mejor manera de evitar cualquier trampa [8]. - Для маорийцев скат Manta Ray был могущественным оберегом. Опасный житель океана был символом свободных и отважных искателей приключений, его сакральная энергия помогала им адаптироваться к любой ситуации и ограждала от негативных эмоций окружающих людей. Кольчо Manta Ray будет надежно вас оберегать и научит обходить подводные камни стороной [9]. Сама по себе фраза «Manta Ray» - иноязычное вкрапление даже для испанского текста. В данном случае эта аллюзия отражает название коллекции и является ее лейтмотивом, поэтому ее появление в тексте перевода целесообразно. Однако, чтобы избежать неправильного понимания данной лексической единицы, переводчик вводит пояснение - помещает перед ней слово «скат», поскольку «Manta Ray» - разновидность ската. По-испански он называется «Manta Raya». Таким образом, при переводе применяется прагматическая адаптация. Данный переводческий прием направлен на преодоление социокультурных различий, препятствующих правильному восприятию рекламы русскоязычной аудиторией.

На основании исследования иноязычных вкраплений в рекламных текстах товаров испанской модной индустрии и их переводов можно сформулировать следующие выводы. Иноязычные вкрапления представлены в испанской рекламе, главным образом, английскими и французскими элементами (словами, фразами, слоганами), варваризмами, лексемами интертекстуального характера, аллюзиями. Выяснено, что выбор способа и приема перевода иноязычных вкраплений обусловлен рядом факторов, связанных как с характером самой лексической единицы (известность, узнаваемость), так и со 
стилистическими и смысловыми особенностями исходного рекламного текста. Установлено, что малоизвестные русскоязычному реципиенту лексемы, как правило, не сохраняются при переводе, равно как не допускается избыточное употребление иностранных слов в рамках одного переводного текста. В таких случаях применяется прямой или приближенный перевод иноязычного вкрапления. В случае перевода аллюзий их первоначальная форма обычно сохраняется; или применяется прием прагматической адаптации, а также объяснительный перевод. С другой стороны, появление неизменен- ного иностранного вкрапления в тексте перевода может быть продиктовано стилистической необходимостью, когда заимствованная лексема подчинена единому создаваемому рекламой образу, или когда рекламируемый товар предназначен для конкретной целевой аудитории и призван вызвать необходимые ассоциации у реципиента. Таким образом, адекватная передача иноязычных вкраплений при переводе испанской рекламы модных товаров способствует реализации основной, апеллятивной функции рекламного текста: заинтересовать и привлечь потенциального покупателя.

\section{ЛИТЕРАТУРА}

1. Борнякова И.В. Специфика языка рекламных сообщений и их перевода в рамках межкультурной коммуникации (на материале немецкой и русской журнальной рекламы): автореф. дис. ... канд. филол. наук. Москва, 2007. 23 с.

2. Коломиец С.В. Иноязычные вкрапления в текстах русских рекламных сообщений // Вестник КемГУ. 2012. №4 (52) Т. 3. С. $268-272$.

3. Мигдаль И.Ю. Культурная маркированность иноязычных вкраплений художественного текста // Вестник Российского университета дружбы народов. Серия: Теория языка. Семиотика. Семантика. 2012. №4. С. 31-36.

4. Официальный сайт Mango: электронный ресурс. Режим доступа URL: https://shop.mango.com/ru/ (дата обращения: 01.12.2020)

5. Швейцер А.Д. Теория перевода: Статус, проблемы, аспекты. М.: Либроком, 2012. 216 с.

6. Ювелирная коллекция - Magerit: электронный ресурс. Режим доступа URL: https://www.mageritjoyas.com/collection.php?col=all\&lang=RU (дата обращения: 01.12.2020)

7. Colecciones - Magerit Joyas: электронный ресурс. Режим доступа URL: https://www.mageritjoyas.com/collection.php?col=all\&lang=ES (дата обращения: 01.12.2020)

8. Giverola Jewelry Store Online: электронный ресурс. Режим доступа URL: https://giverola.net/es/ (дата обращения: 01.12.2020)

9. Jewelry Store Online - Giverola: электронный ресурс. Режим доступа URL: https://giverola.net/ru/ (дата обращения: 01.12.2020)

10. Joyería Online Tous, Joyeros desde 1920: электронный ресурс. Режим доступа URL: https://www.tous.com/es-es/ (дата обращения: 01.12.2020)

11. Rodríguez Arcos, I. Publicidad y estereotipos femeninos: el potencial del traductor contra la violencia simbólica de Bourdieu // Asparkía. 2016. N 27. P. 51-63.

12. Mango España. Moda online: электронный ресурс. Режим доступа URL: https://shop.mango.com/es (дата обращения: 01.12.2020)

13. Tous, ювелиры с 1920 года: электронный ресурс. Режим доступа URL: https://www.tous.ru (дата обращения: 01.12.2020) 